\title{
RIGOR E QUALIDADE NA PESQUISA QUALITATIVA NO BRASIL
}

\author{
Por Maria José Tonelli \\ Professora da FGV-EAESP \\ E-mail: mjtonelli@fgvsp.br
}

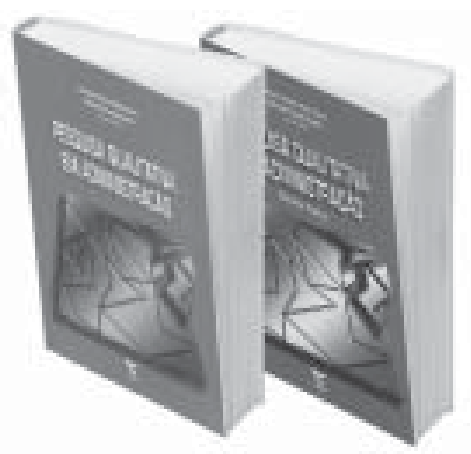

\section{PESQUISA QUALITATIVA EM ADMINISTRAÇÃO}

De Marcelo Milano Falcão Vieira e Deborah Moraes Zouain (Orgs.). Rio de Janeiro: Editora FGV, 2004, 223p.

\section{PESQUISA QUALITATIVA EM ADMINISTRAÇÃO: TEORIA E PRÁTICA}

De Marcelo Milano Falcão Vieira e Deborah Moraes Zouain (Orgs.). Rio de Janeiro: Editora FGV, 2005, 237 p.

Marcelo M. F. Vieira e Deborah M. Zouain, professores da FGV-RJ, são os organizadores destes dois volumes dedicados à pesquisa qualitativa em Administração. A obra é extremamente oportuna para a área, que cresceu muito em quantidade nos últimos anos, mas que tem sido questionada quanto à qualidade de sua produção (veja Bertero, C.; Caldas, M.; Wood Jr., T. Produção acadêmica em Administração no Brasil. São Paulo: Atlas, 2005). As questões metodológicas são apontadas como entraves nas diversas áreas, como estratégia, marketing, tecnologia da informação, estudos organizacionais, recursos humanos à produção de conhecimento que seja consistente e garanta 0 avanço da teoria e das aplicações práticas úteis para a melhoria das organizações no país.
A coletânea também é relevante por dar apoio ao debate que opõe os resultados obtidos em pesquisa quantitativa e qualitativa. De fato, como mostram os organizadores logo na introdução, é possível fazer pesquisa qualitativa com rigor e relevância. Essa oposição não se sustenta se considerarmos que as ciências humanas tratam de questões de natureza bem diversa das ciências exatas. Parece evidente, mas não é possível observar cultura organizacional, por exemplo, com microscópios eletrônicos essenciais para a observação de culturas de bactérias em biologia. Fenômenos diferentes pedem ferramentas apropriadas.

O primeiro volume está dividido em duas partes. A primeira, dedicada às questões teóricas e epistemológicas, traz artigos de autores fundamen- tais para a pesquisa na área. Alketa Peci debate a questão objetividade/ subjetividade a partir do pragmatismo norte-americano de W. James e R. Rorty, e apresenta as contribuições de Bruno Latour como um dos autores que rejeita essa dicotomia; Sérgio Alves, debate a "A atualidade da epistemologia weberiana" e da aplicação dos tipos ideais para a compreensão da complexidade das organizações; Maria Ceci Misoczky apresenta "leituras enamoradas de Marx, Bourdieu e Deleuze" e ThiryCherques trata da fenomenologia de Husserl e Merleau-Ponty como uma abordagem possível para a descrição do cotidiano organizacional. Destaque ao artigo de Marcelo Milano F. Vieira, que inaugura a coletânea e aponta caminhos para que a utilização da pesquisa qualitativa tenha con- 
fiabilidade e permita generalização, mostrando que a oposição entre pesquisa qualitativa e quantitativa não tem razão de ser.

A segunda parte do livro aborda a "aplicação de pesquisa qual itativa em Administração". Alguns artigos apresentam procedimentos de coleta de dados: estudos de casos múltiplos (artigo de Luiz Antonio Jóia), grupo focal (artigo de $M$ arco Aurélio Ruediger e Vicente Riccio) e desenhos (Sylvia Vergara); um artigo debate o uso de métodos qualitativos em pesquisas sobre o comportamento do consumidor (Ayrosa e Sauerbronn); e o livro encerra com o artigo de Paulo Figuei redo sobre questões práticas no desenho de pesquisas empíricas relativas a aprendizagem e inovação industrial no Brasil.

O segundo volume também apresenta artigos teóricos e rel atos de pesquisas no país. Os primeiros capítulos estão voltados para questões conceituais. Martins, no primeiro artigo da coletânea, mostra as múltiplas dimensões do espaço organizacional e propõe uma abordagem semiótica das organizações; Thiry-Cherques discute as diferentes mediações presentes no uso do "modelo estruturalista" para a análise de fenômenos sociais. $N$ a seqüência, Faria apresenta o uso do "realismo crítico" para pesquisas em estratégia, mostrando os limites da abordagem positivista e interpretativista na sel eção de problemas para análise, e traz como exemplo o estudo de redes interorganizacionais. Guedes traz o tema da "Pesquisa internacional em gestão: abordagem interdisciplinar com múltiplos níveis de análise", em que propõe o uso de casos múltiplos analisados nos níveis internacional, nacional, industrial e organizacional. Goulart e Carvalho fazem uma síntese bastante interessante de questões epistemológicas em pesquisa qual itativa e quantitativa, e mostram diferentes procedimentos em coleta de dados. Dellagnel o e Silva apresentam as aplicações da análise de conteúdo em Administração, especialmente a proposta de Bardin na construção de categorias interpretativas de entrevistas, e finalmente Santos aborda "O método qualitativo na investi gação de sentidos: uma proposta multipolar para estudos organizacionais".

Os artigos voltados para a apresentação de resultados de pesquisa incluem o trabalho de Caval canti, que aborda questões específicas de Administração Pública no artigo “Estrutura e ação no setor público brasileiro: a "gerência equalizadora". Aqui o autor discute 0 uso das metáforas na pesquisa e mostra os resultados dos sentidos das ações de gestores públicos. 0 trabalho de Zouain e Torres, a partir de uma pesquisa realizada sobre o processo de inovação tecnológica na Incubadora Tecnológica de Campina Grande, apresenta questões decorrentes do uso de estudo de caso em pesquisa qualitativa.

Infelizmente não é possível apresentar em detalhes, nesta resenha, a contribuição que todos esses artigos trazem, nos dois volumes dessa coletânea, mas é possível afirmar que os artigos desses autores brasileiros suprem sérias lacunas da pesquisa qual itativa em Administração no Brasil.

Entretanto, duas questões ainda nos inquietam após a leitura dos artigos. A primeira é sobre as dificuldades de se fazer pesquisa qualitativa com qualidade - no país e a segunda, sobre os ajustes antrop ofágicos necessários para procedimentos de coleta de dados em países em desenvolvimento. Os artigos apresentados não discutem profundamente essas questões, ainda que nossas inquietações sejam atenuadas pelas contribuições dos artigos de Figueiredo (no primeiro volume) e os de Cavalcanti e de Zouain e Torres (no segundo volume), que tratam de questões específicas da nossa real idade. Esse aspecto é importante, se considerarmos, como Prasad (veja em Crafting Qualitative Research: Working in the Post-Positivist Traditions. New York: M. E. Sharpe, Inc., 2005), o pós-colonialismo, ou seja, a reprodução, sem questionamentos e/ou adaptações para os problemas locais, de metodologias adequadas apenas para o primeiro mundo. $M$ as, apesar deste aspecto, o livro tem o mérito de apresentar pesquisas e autores brasileiros!

Outro ponto a ser refletido é que, embora os volumes tragam artigos em áreas como, por exemplo, marketing, trata-se de uma obra que privilegia as áreas de estratégia e de estudos organizacionais. Não há nenhum problema nesse recorte, mas questões importantes de outras áreas da Administração, como, por exemplo, a tecnologia da informação, não foram contempladas.

Além disso, como os dois volumes não indicam com clareza os artigos de cunho epistemológico e aquel es referentes aos procedimentos de coleta de dados, sugere-se, para futuras re-edições, uma reorganização dos artigos. Essa simples mudança, especialmente no segundo volume, poderia ser didaticamente útil para os leitores, especialmente os alunos de pós-graduação, que, com certeza, vão se beneficiar muito com a leitura de todos os textos aqui apresentados.

Para finalizar, ressaltamos a relevância desta obra para o desenvolvimento da academia em Administração no país. Os artigos aqui reunidos fornecem recursos necessários para o esclarecimento de aspectos metodológicos essenciais para o rigor na pesquisa qualitativa. 